\title{
Changes in Doppler indices of cardiac function during and after percutaneous transluminal coronary angioplasty
}

Anthony C Hunt, Simon C Chow, Javier Escaned, Ralph A Perry, Ashok Seth, Man-Fai Shiu

\section{Abstract}

Objective-To assess the sensitivities of Doppler indices to changes in global cardiac function during and after controlled myocardial ischaemia induced by coronary angioplasty.

Design-Continuous wave Doppler signals of aortic flow were recorded during coronary angioplasty. The following Doppler indices of cardiac function were measured before, during, and after balloon inflation: $V$ (peak velocity), MA (mean acceleration), $V^{2} / T$ ( $T=$ time from onset to peak ejection), and $M D$ (minute distance corrected for baseline heart rate).

Setting-A tertiary care cardiological unit in a university hospital.

Patients-Sixteen patients undergoing coronary angioplasty of the left anterior descending coronary artery. Eight patients had multivessel disease.

Main outcome measures-The primary outcome measures were planned before data collection began.

Results-12 patients showed a significant fall of three or more Doppler indices from their baseline values during balloon inflation. This occurred in all patients with multivessel disease. The Doppler indices $V^{2} T, M D, V$, and $M A$ fell by $43 \cdot 7 \%, 37 \cdot 7 \%, 27 \cdot 4 \%$, and $23 \%$ respectively from their baseline values $(p<0.001)$. The relative sensitivities of the Doppler indices to ischaemia were $V^{2} / T>M D \quad(p<0.02), \quad M D>$ $(p<0.001)$, and $V>M A(p<0.01)$. The impairment of global left ventricular function resulting from brief balloon inflation during single vessel angioplasty was reversible in all the patients.

Conclusions-The Doppler indices $V^{2} / T, M D, V$, and $M A$ are all sensitive, in order of magnitude, to falls in global cardiac function resulting from ischaemia. They may prove useful for assessing cardiac function during ischaemia in the clinical setting.

$S$ C Chow

J Escaned

R A Perry

A Seth

M-F Shiu

Correspondence to Dr Anthony C Hunt University Department of Cardiovascular Medicine, Queen Elizabeth Hospital, Edgbaston,

Birmingham B15 2TH.

Accepted for publication 25 June 1991

Balloon inflation during percutaneous transluminal coronary angioplasty produces considerable global and regional impairment of left ventricular function..$^{1-3}$ This impairment was reversible after brief periods of balloon occlusion in cases of angioplasty in single vessel disease. ${ }^{34} \mathrm{~A}$ carefully controlled study has shown that after balloon deflation, indices of left ventricular systolic function return to normal within $40 \mathrm{~s}$ of reperfusion. ${ }^{5}$ The changes in various Doppler indices of cardiac function during myocardial ischaemia have been studied in $\operatorname{dogs}^{6}$ and in the exercising patient. ${ }^{78}$ Doppler echocardiography has been successful in demonstrating changes in left ventricular function during angioplasty ${ }^{9}$ but there has been little written about the relative sensitivities of Doppler indices in the angioplasty model of ischaemia. The purpose of this study was to assess the sensitivities of various Doppler indices to changes of cardiac function during and after coronary artery balloon occlusion.

\section{Patients and methods}

PATIENTS

We studied 16 patients (two women and 14 men), mean age 55 (range 40-70) years. Patients had stable limiting angina despite medical treatment. All the patients were in sinus rhythm and none had valve disease. Each patient gave informed verbal consent before the start of the study. Before enrolment patients were assessed for the presence of a suprasternal echocardiographic window that gave clean continuous Doppler signals of ascending aortic flow.

\section{CORONARY ANATOMY}

The 16 patients enrolled in the study required left anterior descending coronary artery angioplasty. The target stenoses had a mean value of 84\% (range 75-90) and all allowed anterograde flow of contrast. Eight patients had single vessel disease and eight patients multivessel disease. In the multivessel disease group the diseased vessels associated with the target vessel had stenoses with a mean value of $75.8 \%$ (range 50 100) (table 1). None of the patients with single vessel disease had significant collateral supply to the target vessel. Of the eight patients with multivessel disease, four had ventriculographic evidence of pre-existing mild myocardial hypokinesia in the territory of the non-target vessel. These four patients had occlusions of their right coronary arteries, with three of them receiving a collateral supply (Rentrop grade

There was no significant difference in the left ventricular ejection fractions between the groups of patients with single vessel and multivessel disease: mean values were 
Table 1 Distribution of coronary artery disease in patients with multivessel disease undergoing angioplasty

\begin{tabular}{llrrl}
\hline Patients & $\begin{array}{l}\text { Target LAD } \\
(\%)\end{array}$ & $\begin{array}{c}\text { RCA } \\
(\%)\end{array}$ & $\begin{array}{l}\text { LCx } \\
(\%)\end{array}$ & Collaterals \\
\hline 1 & 85 & 100 & 0 & LAD $\rightarrow$ RCA (3) \\
2 & 95 & 100 & 50 & 0 \\
3 & 90 & 50 & 0 & 0 \\
4 & 80 & 100 & 50 & LAD $\rightarrow$ RCA (4) \\
5 & 80 & 0 & 60 & 0 \\
6 & 90 & 50 & 90 & 0 \\
7 & 80 & 0 & 70 & 0 \\
8 & 70 & 100 & 90 & LAD $\rightarrow$ RCA (4) \\
\hline
\end{tabular}

LAD, left anterior descending coronary artery; LCx circumflex coronary artery; RCA, right coronary artery; Rentrop gradings in parentheses.

$52 \%$ (range 40-65) and 69\% (range 32-90) respectively.

PROTOCOL FOR PERCUTANEOUS TRANSLUMINAL CORONARY ANGIOPLASTY

All patients underwent angioplasty from the right femoral artery after insertion of an arterial sheath. A standard drug regimen was started at least 48 hours before the procedure. $\beta$-Blocking drugs were stopped and the patients were started on oral $300 \mathrm{mg}$ aspirin, $20 \mathrm{mg}$ nifedipine, and $10 \mathrm{mg}$ isosorbide dinitrate. An infusion of isosorbide dinitrate $(3 \mathrm{mg} / \mathrm{h})$ was started two hours before and continued throughout the procedure and patients were fully heparinised. We used non-ionic contrast medium and a steerable guide wire angioplasty system.

\section{DOPPLER SYSTEM}

Ascending aortic blood velocity was evaluated transcutaneously from the suprasternal notch by a conventional continuous wave Doppler transmitter and a receiver operating at 2.0 $\mathrm{MHz}$ (Doptek decoder). The transducer was mounted on a spring loaded carriage held in a constant position by an adjustable frame. The position of the mechanical frame holding the transducer was set when a clean, continuous Doppler signal of maximum amplitude was obtained. Occasionally the transducer position was moved inadvertently by the patient but its position was rapidly corrected and a verbal note made into a roving microphone. This enabled us to avoid analysing unrepresentative Doppler signals recorded at the time of readjustment of the transducer. The received Doppler-shifted blood velocity signal was processed by Fourier analysis at a sampling rate of $5 \mathrm{~ms}$ and a spectral velocity envelope was displayed. Digital callipers allowed measurement of peak velocity to the nearest $\mathrm{cm} / \mathrm{s}$ and time to the nearest $2.5 \mathrm{~ms}$.

All signals obtained throughout the angioplasty procedure were recorded on to magnetic tape by an on line tape recording system. A roving microphone with an input into the recording system allowed events to be verbally recorded simultaneously with the recording of the Doppler signal.

\section{DOPPLER MEASUREMENTS}

Continuous wave Doppler recordings were obtained in supine patients at rest within the catheter laboratory throughout the angioplasty procedure. Digital callipers were used to measure peak velocity (V), time from onset of signal to peak velocity ( $\mathrm{T})$, heart rate, and stroke distance from the recorded signals. These measurements were made from five clear, nearly consecutive Doppler signals obtained at each of the following times: just before an inflation (baseline), at the end of a balloon inflation, and $120 \mathrm{~s}$ after balloon deflation. A mean of 8.7 consecutive signals (range 5-14) were measured on the initial baseline, and timing these as close to balloon inflation as possible allowed most of these measurements to be made at the time the deflated balloon catheter was across the lesion.

DATA ANALYSIS

We calculated $\mathrm{V}^{2} / \mathrm{T}$ (a correlate of peak $\mathrm{dP} / \mathrm{dt}$ ) and MA (mean acceleration $=\mathrm{V} / \mathrm{T}$ ) from all measurements of $V$ and $T$. The Doppler indices $V, V^{2} / T$, and $M A$ were considered as indicators of the contractile state and minute distance corrected for baseline heart rate (MD) as an index of cardiac output. Corrected minute distance was calculated as stroke distance $\times$ baseline heart rate.

The standard deviation (SD) and coefficient of variation were calculated for the initial baseline values of heart rate, V, MA, MD, and $\mathrm{V}^{2} / \mathrm{T}$. We considered that subsequent changes in the magnitude of the Doppler indices that occured during balloon inflation were significant if the mean value decreased more than two SDs calculated from the initial baseline. Significant changes in cardiac function were deemed to occur in a patient during balloon inflation if three or more of the Doppler indices V, MA, $\mathrm{V}^{2} / \mathrm{T}$, and $\mathrm{MD}$ were significantly depressed.

For those patients showing a significant change in cardiac function during balloon inflation, the percentage change of a Doppler index from its baseline value was calculated as

$\%$ change $=\frac{\text { baseline value }- \text { inflation value }}{\text { baseline value }} \times 100$

Significant differences in the magnitude of change for each of these Doppler indices during a balloon inflation were analysed to determine the relative sensitivity of each Doppler index to the ischaemic insult. Analysis was by statistical comparison of the percentage change from the baseline of each Doppler index during the inflation period and at $120 \mathrm{~s}$ after the final inflation.

\section{STATISTICAL ANALYSIS}

The SD and coefficient of variation were calculated from the initial baseline values for each Doppler index. Subsequent changes in the indices were considered significant if they exceeded twice the SD. A two tailed $t$ test was used to determine the significance of any change in the Doppler index. A paired $t$ test was used to find the relative sensitivities of Doppler indices to changes in cardiac function. Statistics were performed on a Hewlett Packard HP$28 \mathrm{~S}$ scientific calculator and with an Oxstat statistical package.

\section{Results}

Sixteen patients had a total of 33 inflations with 
Table 2 Mean values of baseline Doppler indices for inflations in patients showing significant reductions in three Doppler indices during angioplasty

\begin{tabular}{|c|c|c|c|c|c|c|c|c|c|c|c|c|c|c|c|c|c|c|c|}
\hline \multirow[b]{2}{*}{ Patient } & \multicolumn{5}{|c|}{ 1st Inflation } & \multicolumn{5}{|c|}{ 2nd Inflation } & \multicolumn{5}{|c|}{ 3rd Inflation } & \multicolumn{4}{|c|}{ 4th Inflation } \\
\hline & $H R$ & $V$ & $V^{2} / T$ & $M A$ & $M D$ & $H R$ & $\boldsymbol{V}$ & $V^{2} / T$ & $M A$ & $M D$ & $H R$ & $V$ & $V^{2} / T$ & $M A$ & $M D$ & $H R V$ & $V^{2} / T$ & $M A$ & $M D$ \\
\hline $\begin{array}{r}1 \\
2 \\
3 \\
4 \\
5 \\
6 \\
7 \\
8 \\
9 \\
10 \\
11 \\
12 \\
\end{array}$ & $\begin{array}{r}66 \\
61 \\
73 \\
58 \\
93 \\
\\
73 \\
91 \\
54 \\
120 \\
85 \\
77 \\
\end{array}$ & $\begin{array}{l}65 \cdot 2 \\
71 \cdot 8 \\
81 \cdot 8 \\
62 \cdot 8 \\
66 \cdot 3 \\
\\
57 \cdot 4 \\
50 \\
88 \cdot 5 \\
47 \cdot 8 \\
67 \\
73 \\
\end{array}$ & $\begin{array}{c}57 \cdot 7 \\
103 \\
128 \\
61 \cdot 7 \\
69 \cdot 2 \\
\\
52 \\
29 \\
121 \\
32 \cdot 1 \\
93 \\
100 \\
\end{array}$ & $\begin{array}{l}0.88 \\
1.43 \\
1.56 \\
0.98 \\
1.04 \\
\\
0.91 \\
0.58 \\
1.39 \\
0.67 \\
1.39 \\
1.4 \\
\end{array}$ & $\begin{array}{l}720 \\
660 \\
858 \\
621 \\
824 \\
\\
790 \\
830 \\
696 \\
941 \\
574 \\
717 \\
\end{array}$ & $\begin{array}{r}66 \\
84 \\
89 \\
56 \\
95 \\
\\
117 \\
64\end{array}$ & $\begin{array}{l}72 \\
70 \\
43 \\
57 \\
56 \\
\\
54 \\
79\end{array}$ & $\begin{array}{l}86 \cdot 4 \\
71 \\
23 \cdot 7 \\
55 \\
41 \cdot 8 \\
\\
43 \cdot 5 \\
138\end{array}$ & $\begin{array}{l}1.2 \\
1.01 \\
0.55 \\
0.97 \\
0.75 \\
\\
0.81 \\
1.75\end{array}$ & $\begin{array}{l}818 \\
863 \\
746 \\
590 \\
874 \\
\\
779 \\
629\end{array}$ & $\begin{array}{l}60 \\
92 \\
59 \\
92 \\
92\end{array}$ & $\begin{array}{l}71 \\
45 \\
57 \\
48\end{array}$ & $\begin{array}{l}85 \cdot 9 \\
27 \\
57 \\
34\end{array}$ & $\begin{array}{l}1.2 \\
0.6 \\
1.0 \\
0.71\end{array}$ & $\begin{array}{l}786 \\
925 \\
602 \\
811\end{array}$ & $90 \quad 50$ & $34 \cdot 2$ & 0.69 & 754 \\
\hline \multicolumn{20}{|c|}{$\begin{array}{l}\text { HR, heart rate (beats } / \mathrm{min}) ; \mathrm{V} \text {, peak velocity }(\mathrm{cm} / \mathrm{s}) ; \mathrm{T} \text {, time from onset to peak velocity }(\mathrm{s}) ; \mathrm{MD} \text {, minute distance corrected for } \\
\text { baseline heart rate }(\mathrm{cm}) ; \mathrm{MA} \text {, mean acceleration }\left(\mathrm{cm} / \mathrm{s}^{2} \times 10^{3}\right) \text {. Patients } 1-8 \text {, multivessel disease; patients } 9-12 \text {, single vessel } \\
\text { disease. }\end{array}$} \\
\hline \multicolumn{20}{|c|}{$\begin{array}{l}\text { Table } 3 \text { Mean values of Doppler indices after } 60 \text { s inflation in patients showing significant reductions in three Doppler } \\
\text { indices during angioplasty }\end{array}$} \\
\hline & \multicolumn{5}{|c|}{ 1st Inflation } & \multicolumn{5}{|c|}{ 2nd Inflation } & \multicolumn{5}{|c|}{ 3rd Inflation } & \multicolumn{4}{|c|}{ 4th Inflation } \\
\hline Patient & $H R$ & $V$ & $V^{2} / T$ & $M A$ & $M D$ & $H R$ & $V$ & $V^{2} / T$ & $M A$ & $M D$ & $H R$ & $V$ & $V^{2} / T$ & $M A$ & $M D$ & $H R V$ & $V^{2} / T$ & $M A$ & $M D$ \\
\hline $\begin{array}{r}1 \\
2 \\
3 \\
4 \\
5 \\
6 \\
7 \\
8 \\
9 \\
10 \\
11 \\
12\end{array}$ & $\begin{array}{r}\frac{67}{58} \\
63 \\
72 \\
\underline{92} \\
\frac{61}{95} \\
62 \\
\frac{121}{90} \\
69\end{array}$ & $\begin{array}{l}44 \\
39 \\
71 \cdot 6 \\
29 \\
60 \\
56\end{array}$ & $\begin{array}{l}\frac{61 \cdot 5}{51} \\
64 \\
40 \\
\underline{56 \cdot 5} \\
32 \cdot 8 \\
20 \cdot 8 \\
79 \\
12 \cdot 9 \\
65 \\
56\end{array}$ & $\begin{array}{l}0.75 \\
0.53 \\
1.1 \\
0.45 \\
1.09 \\
1.0\end{array}$ & $\begin{array}{l}416 \\
505 \\
442 \\
531 \\
420 \\
631\end{array}$ & $\begin{array}{l}51 \\
\frac{84}{90} \\
\frac{97}{57} \\
94\end{array}$ & $\begin{array}{l}58 \\
58 \\
29 \\
39 \\
39\end{array}$ & $\begin{array}{c}55 \cdot 7 \\
48 \cdot 1 \\
15 \cdot 3 \\
28 \cdot 2 \\
22 \cdot 4 \\
\\
11 \cdot 6 \\
\underline{125}\end{array}$ & $\begin{array}{l}0.96 \\
0.82 \\
0.53 \\
0.72 \\
0.57\end{array}$ & $\begin{array}{l}459 \\
755 \\
357 \\
335 \\
448\end{array}$ & $\begin{array}{l}53 \\
\frac{93}{60} \\
\frac{91}{1}\end{array}$ & $\begin{array}{l}25 \\
41 \\
39\end{array}$ & $\begin{array}{c}47 \cdot 7 \\
8 \cdot 9 \\
28 \\
22\end{array}$ & $\begin{array}{l}0.93 \\
0.35 \\
0.68 \\
0.56\end{array}$ & $\begin{array}{l}411 \\
375 \\
400 \\
442\end{array}$ & $\underline{89} 36$ & $20 \cdot 7$ & 0.57 & 396 \\
\hline
\end{tabular}

For explanations see footnote to table 2 . Underlined figures indicate no significant reduction in values from baseline.

Table 4 Initial and final baseline mean values of Doppler indices in patients showing significant reductions in three Doppler indices during angioplasty

\begin{tabular}{|c|c|c|c|c|c|c|c|c|c|c|}
\hline \multirow[b]{2}{*}{ Patient } & \multicolumn{5}{|l|}{ Initial baseline } & \multicolumn{5}{|c|}{ Final baseline } \\
\hline & $H R$ & $V$ & $V^{2} / T$ & $1 A$ & $M D$ & $H R$ & $\boldsymbol{V}$ & $V^{2} / T$ & $M A$ & $M D$ \\
\hline $\begin{array}{r}1 \\
2 \\
3 \\
4 \\
5 \\
6 \\
7 \\
8 \\
9 \\
10 \\
11 \\
12\end{array}$ & $\begin{array}{l}66(0)(0) \\
61(1 \cdot 13)(2) \\
73(0 \cdot 89) \\
58(1 \cdot 1)(2) \\
93(0 \cdot 6)(0 \cdot 7) \\
90(0 \cdot 8)(0 \cdot 9) \\
73(7 \cdot 6)(10) \\
91(1 \cdot 2)(1) \\
54(0 \cdot 7)(1) \\
120(0 \cdot 7)(0 \cdot 6) \\
85(1 \cdot 9)(2) \\
77(0 \cdot 8)(1)\end{array}$ & $\begin{array}{l}65 \cdot 2(3 \cdot 2)(5) \\
71 \cdot 8(4 \cdot 2)(6) \\
81 \cdot 8(4 \cdot 2)(5) \\
62 \cdot 8(1 \cdot 5)(2) \\
66 \cdot 3(3 \cdot 2)(5) \\
46 \cdot 5(2 \cdot 9)(6) \\
57 \cdot 4(1 \cdot 64)(3) \\
50(2 \cdot 4)(5) \\
88 \cdot 5(3 \cdot 1)(4) \\
47 \cdot 8(2 \cdot 95)(6) \\
67(1 \cdot 6)(2) \\
73(4 \cdot 3)(6)\end{array}$ & $\begin{array}{c}57 \cdot 7(11 \cdot 9)(20) \\
103(14)(14) \\
128(21 \cdot 6)(17) \\
61 \cdot 7(3 \cdot 2)(5) \\
69 \cdot 2(9 \cdot 7)(14) \\
27 \cdot 8(3 \cdot 6)(13) \\
52(4 \cdot 6)(9) \\
29(1 \cdot 6)(6) \\
121(8 \cdot 9)(7) \\
32 \cdot 1(3 \cdot 9)(12) \\
93(8 \cdot 4)(9) \\
100(15 \cdot 4)(15)\end{array}$ & $\begin{array}{l}0.88(0.14)(16) \\
1.43(0.14)(10) \\
1.56(0.22)(14) \\
0.98(0.04)(4) \\
1.04(0.1)(10) \\
0.57(0.07)(12) \\
0.91(0.07)(8) \\
0.58(0.03)(5) \\
1.39(0.08)(6) \\
0.67(0.05)(7) \\
1.4(0.11)(8) \\
1.4(0.18)(12)\end{array}$ & $\begin{array}{l}720(44 \cdot 6)(6) \\
660(100)(15) \\
858(89)(10) \\
621(39)(6) \\
824(54)(6) \\
710(69)(10) \\
790(91 \cdot 2)(11) \\
830(70)(8) \\
696(44)(6) \\
941(50)(5) \\
574(44)(8) \\
717(36)(5)\end{array}$ & $\begin{array}{l}64 \\
56 \\
52 \\
54 \\
84 \\
93 \\
61 \\
90 \\
57 \\
77 \\
78 \\
71\end{array}$ & $\begin{array}{r}71 \\
74 \\
112 \\
65 \\
68 \\
59 \\
56 \\
54 \\
89 \\
61 \\
90 \\
75\end{array}$ & $\begin{array}{l}74 \cdot 1 \\
96 \\
208 \\
76 \cdot 7 \\
68 \\
51 \cdot 2 \\
52 \\
41 \cdot 1 \\
121 \\
53 \cdot 9 \\
147 \\
102\end{array}$ & $\begin{array}{l}1.0 \\
1.3 \\
1.9 \\
1.18 \\
1.0 \\
0 \cdot 87 \\
0.93 \\
0.76 \\
1.36 \\
0.88 \\
1.7 \\
1.36\end{array}$ & $\begin{array}{l}794 \\
509 \\
642 \\
650 \\
819 \\
964 \\
618 \\
757 \\
481 \\
662 \\
890 \\
923\end{array}$ \\
\hline
\end{tabular}

Initial baseline values and mean (SD) (coefficient of variation \%). Final baseline values are means only. For other explanations see footnote to table 2 .

a mean duration of $58 \cdot 5 \mathrm{~s}$ per inflation. Fifteen inflations were performed in patients with single vessel disease and 18 inflations in patients with multivessel disease. Of the 16 patients undergoing angioplasty, 12 had significant falls $(\mathrm{p}<0.001)$ in three or more Doppler indices during one or more inflations. This occurred in all patients with multivessel disease (tables 2 and 3). We found no significant fall in Doppler indices when the first baseline was compared with the final baselines (table 4). In fact a significant increase $(p<0.001)$ in two or more Doppler indices occurred in five patients $(31 \%)$ at $120 \mathrm{~s}$ after the end of the final inflation. Three of these five patients had single vessel disease and two had multivessel disease. The relative sensitivities of the Doppler indices to changes in cardiac function were $\mathrm{V}^{2} / \mathrm{T}, \mathrm{MD}, \mathrm{V}$, and $\mathrm{MA}$ in order of magnitude. The significance levels in comparisons between $\mathrm{V}^{2} / \mathrm{T}$ and $\mathrm{MD}, \mathrm{MD}$ and $\mathrm{V}$, and $\mathrm{V}$ and $\mathrm{MA}$ were $\mathrm{p}<0.02, \mathrm{p}<0.001$, and $p<0.01$ respectively (table 5 ).

\section{Discussion}

This is the first report of the relative sensitivities of Doppler indices to changes in global cardiac function that occur during controlled myocardial ischaemia produced by coronary angioplasty. Angioplasty produces a regional myocardial dysfunction in the mass of cardiac muscle supplied by the coronary artery undergoing balloon occlusion and, as in this study, past reports have also shown changes in 
Table 5 Mean percentage change (SD) in Doppler indices of all patients having significant falls in three Doppler indices during balloon inflation and the relative sensitivities of these Doppler indices to change

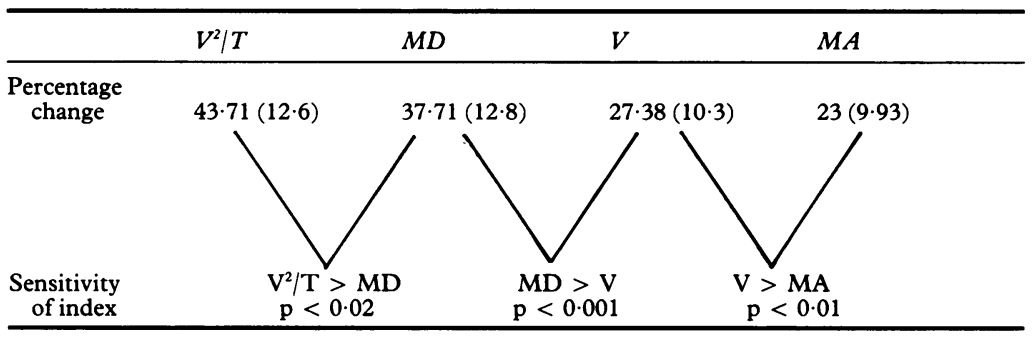

For explanations see footnote to table 2 .

global cardiac function during angioplasty. ${ }^{1}$ The global left ventricular function that results from balloon occlusion represents an interplay between the reduced contractility of the ischaemic region of myocardium and the compensating hypercontractility of the nonischaemic cardiac muscle. For this reason, while indices of global left ventricular function are not an accurate measure of regional myocardial dysfunction they do reflect overall haemodynamic cardiac performance in a patient during an ischaemic insult. Doppler echocardiography has advantages over other techniques for assessment of global left ventricular function during angioplasty; it is entirely non-invasive and allows continuous recording during and after each coronary occlusion. Cross sectional echocardiography successfully detects changes in left ventricular wall motion during balloon occlusion of the coronary artery. ${ }^{2411}$ Doppler echocardiography has been used to detect changes in left ventricular function during angioplasty in patients with poor collateral supply to their target vessel. ${ }^{9}$ The disadvantages of Doppler echocardiography are variability of sampling axis, beat to beat variability in signal size, and interobserver variation. In our study we held the transducer sampling axis constant in relation to the patient by mounting the transducer on an adjustable metal frame. The same operator made measurements on all Doppler signals. We lessened the effect of beat to beat variability by averaging the measurements from five nearly consecutive Doppler signals recorded immediately before and at the end of the balloon inflation. It was difficult always to obtain consecutive signals of requisite quality but when this situation arose, we chose signals that were nearly consecutive. We considered a significant change in the value of a Doppler index to have occurred if the change in magnitude exceeded two SDs as calculated from the initial baseline.

In some patients the baseline values of the Doppler indices fluctuated substantially between inflations. This may have resulted from the smaller number of Doppler signals measured to obtain subsequent baseline values after the initial baseline recording. Therefore, in some cases, a decline in the values of Doppler indices from their baselines occurring during the balloon inflations after the first inflation may have under or overestimated the real magnitude of change in the Doppler index. This potential error has been reduced by ensuring that analysis of changes of individual
Doppler indices was undertaken only in those patients who had a fall in three or more Doppler indices from their baseline. This improved the specificity when the changes that occurred within an individual Doppler index were analysed. Furthermore, all four Doppler indices fell in all inflations after the first, except for patient 6 . We found a fall in MD during all inflations after the first in every patient. This more functional Doppler index of cardiac function was measured from reference points on the Doppler signal that were different from those used in measuring the other indices. This adds further support to the view that the significant falls from the baselines in Doppler indices, during balloon inflation, reflect real decreases in global cardiac function and that the apparent variability in the baseline values has not led us to false conclusions.

Doppler echocardiography to measure peak acceleration has been used to assess systolic function during angioplasty ${ }^{9}$; other studies have used the Doppler determined stroke integral index of mitral inflow ${ }^{12}$ to investigate changes of cardiac function during angioplasty. The Doppler indices measured in this study are all indicators of global systolic left ventricular performance. Mean acceleration has been used effectively to assess changes in left ventricular contractility during myocardial ischaemia. ${ }^{13}$ The index of peak velocity has been shown to be significantly reduced during ischaemia in animal ${ }^{614}$ and clinical studies. ${ }^{75}$ In a previous study we showed a good correlation between the index $\mathrm{V}^{2} / \mathrm{T}$ and left ventricular peak $\mathrm{dP} /$ dt. ${ }^{16}$ Doppler indices incorporating $V$ were not significantly affected by heart rate. ${ }^{613}$ Consequently we did not correct the Doppler indices $\mathrm{V}, \mathrm{MA}$, and $\mathrm{V}^{2} / \mathrm{T}$ for heart rate in our study. Indices of cardiac output are affected by heart rate $^{6}$ and we corrected the minute distance accordingly. Although aortic pressure influences peak velocity, ${ }^{6}$ previous careful study has not shown a significant change in mean aortic pressure during angioplasty. ${ }^{3}$

\section{CHANGES IN DOPPLER INDICES OF LEFT} VENTRICULAR FUNCTION DURING INFLATIONS We defined changes in cardiac function during an inflation as significant if three or more Doppler indices decreased significantly from the baseline during that inflation. This definition increases the specificity of the positive results at the expense of the sensitivity. The finding of significant lowering of Doppler indices of cardiac function during balloon inflation accords with other reports that have shown decreases in Doppler indices and invasive indices of cardiac function. ${ }^{139}$ In four patients with single vessel disease no significant fall in Doppler indices occurred during balloon occlusion. This may have been due to a compensating hypercontractility of the nonischaemic myocardium or possibly recruitment of a collateral circulation..$^{10}$

\section{CHANGES OF DOPPLER INDICES OF LEFT} VENTRICULAR FUNCTION AFTER INFLATION We found no difference in the size of reductions in Doppler indices when we compared the first 
inflations with the last inflations and the first baselines with final baselines. This supports other studies that found a reversible impairment of left ventricular function after brief periods of ischaemia. ${ }^{35}$ The conditions for the occurrence of a prolonged impairment of left ventricular function were optimal in the patients with multivessel disease and apparent lack of collateral supply to the target vessel. In particular the four patients with occluded right coronary arteries and mild myocardial hypokinesia would have been susceptible to prolonged impairment. Yet in our study this group of patients tolerated the after-effects of ischaemia as well as patients with single vessel disease. In $31 \%$ of patients there was a significant rise in the Doppler indices at $120 \mathrm{~s}$ after the final inflation. This increase in the value of Doppler indices occurred both in patients who did and those who did not show a fall in the Doppler indices of cardiac function during balloon inflation. It was also not related to the presence or absence of multivessel disease. This phenomenon has been described previously and hypercontractility of the reperfused myocardial wall ${ }^{4}$ secondary to reactive hyperaemia in the target vesse ${ }^{17}$ probably accounts for it.

\section{SENSITIVITY OF DOPPLER INDICES TO CHANGES IN LEFT VENTRICULAR FUNCTION}

The Doppler indices of contractility $\left(\mathrm{V}^{2} / \mathrm{T}\right)$ and cardiac output (MD) were the most sensitive indicators of changing cardiac performance after the ischaemic insult of angioplasty. Both of these indices are more sensitive than $\mathrm{V}$, which is known to be very sensitive to changes in left ventricular performance. ${ }^{13}$ The indices $\mathrm{V}^{2} / \mathrm{T}$ and $\mathrm{MD}$ are indicators of global cardiac contractility and cardiac output respectively. As such, they give a dynamic as well as functional assessment of global cardiac performance, much like the use of ejection fractions. The value of using Doppler indices of cardiac function lies in their ability to monitor non-invasively and continuously the changes in global cardiac performance that occur during and after myocardial ischaemia in an individual patient. They do not measure the regional myocardial dysfunction and are therefore not a useful measurement of the mass of ischaemic myocardium.

In conclusion, we used Doppler indices of aortic blood flow to measure changes in cardiac function during balloon occlusion of the coronary arteries. We have shown that the indices $\mathrm{V}^{2} / \mathrm{T}, \mathrm{MD}, \mathrm{V}$, and $\mathrm{MA}$ are sensitive to changes in global cardiac function during balloon occlusion. The more sensitive indices, $\mathrm{V}^{2} / \mathrm{T}$ and $\mathrm{MD}$, may be useful in clinical practice to assess global changes in cardiac performance.

1 Norell MS, Lyons JP, Gershlick AH, et al. Assessment of left ventricular performance during percutaneous transluminal coronary angioplasty: a study by intravenous digital subtraction ventriculography. $\mathrm{Br}$ Heart J 1988;59:419-28.

2 Hauser AM, Gangadharan V, Ramos RG, et al. Sequence of mechanical electrocardiographic and clinical effects of repeated coronary artery occlusion in human beings: echocardiographic observations during coronary angioplasty. J Am Coll Cardiol 1985;5:193-7.

3 Serruys PW, Wijns W, Van den Brand $M$, et al. Left ventricular performance, regional blood flow, wall motion and lactate metabolism during transluminal angioplasty. Circulation 1984;70:25-36.

4 Wohlgelernter D, Cleman M, Highman HA, et al. Regional myocardial dysfunction during coronary angioplasty: evaluation by 2 -dimensional echocardiography and 12 lead electrocardiography. J Am Coll Cardiol 1986;7: l245-54.

5 Carlson EB, Hinohara T, Morris KG. Recovery of systolic and diastolic left ventricular function after 60 -second coronary arterial occlusion during percutaneous transluminal coronary angioplasty for angina pectoris. $\mathrm{Am} \mathrm{J}$ Cardiol 1987;60:460-6.

6 Mathius DW, Wann LS, Sagar KB, et al. The effect of myocardial ischaemia on Doppler echocardiographic indexes of left ventricular performance: influence of heart rate, aortic blood pressure and size of the ischaemic zone. Am Heart $J$ 1988;116:953-60

7 Mehta N, Bennett D, Mannering D, et al. Usefulness of noninvasive Doppler measurement of ascending aortic blood velocity and acceleration in detecting impairment of the left ventricular functional response to exercise three weeks after acute myocardial infarction. Am J Cardiol weeks after acute

8 Harrison MR, Smith MD, Friedman JB, et al. Uses and limitations of exercise Doppler echocardiography in the diagnosis of ischaemic heart disease. J Am Coll Cardio 1987;10:809-17.

9 Khaja F, Sabbah HN, Brymer JF, et al. Influence of coronary collaterals on left ventricular function in patients under going coronary angioplasty. Am Heart $J$ 1988;116: $1174-80$.

10 Rentrop KP, Cohen M, Blanke H, et al. Changes in collatera channel filling immediately after controlled coronary artery occlusion by an angioplasty balloon in human subjects. J Am Coll Cardiol 1985;5:587-92.

11 Alam M, Khaja F, Brymer J, et al. Echocardiographic evaluation of left ventricular function during coronary artery angioplasty. Am J Cardiol 1986;57:20-5.

12 Labovitz AJ, Lewen MK, Kern M, et al. Evaluation of left ventricular systolic and diastolic dysfunction during transient myocardial ischaemia produced by angioplasty. transient myocardial ischaemia prod

13 Wallmeyer K, Wann LS, Sagar KB, et al. The influence of preload and heart rate on Doppler echocardiographic indexes of left ventricular performance: comparison with invasive indexes in experimental preparation. Circulation 1986;74:181-6.

14 Sabbah HN, Przybylski J, Albert DE, et al. Peak aortic blood acceleration reflects the extent of left ventricular ischaemic mass at risk. Am Heart J 1987;113:885-90.

15 Bryg RJ, Labovitz AJ, Mehdirah AA, et al. Effect of coronary artery disease on Doppler-derived parameters of aortic flow during upright exercise. Am J Cardiol 1986;58:14-9.

16 Hunt AC, Perry RA, Seth A, et al. Non-invasive determination of $\mathrm{dP} / \mathrm{dt} \max$ by continuous wave Doppler echocardiography of aortic blood flow [abstract]. J Am Coll Cardiol 1989;13:60a.

17 Pagani M, Vatner SF, Baig $\mathrm{H}$, et al. Initial myocardia adjustments to brief periods of ischaemia and reperfusion in the conscious dog. Circ Res 1978;43:83-92. 